УДК.314.82

СОЦИОЛОГИЧЕСКИЙ АНАЛИЗ СЛОЖИВШЕЕСЯ ПОЛОЖЕНИЕ ИНСТИТУТА СЕМЬИ В КАЗАХСТАНЕ

DOI: $10.31618 /$ ESU.2413-9335.2019.6.69.506

Рахметова P.У

д.э.н., профессор,

Жакенова К.А.

К.C.H.

Андекина Р.Э.

$P h D$,

Иргебаева Н.М.

к.п.н., доиент

Университет Туран-Астана, Казахстан

\title{
SOCIOLOGICAL ANALYSIS OF CURRENT SITUATION OF THE FAMILY INSTITUTION IN KAZAKHSTAN
}

Rakhmetova R.U.

d.e.s., professor

Zhakenova K.A.

C.S.S.

Andekina R.E.

$P h D$

Irgebayeva N.M.

c.p.s., docent

Turan-Astana University, Kazakhstan

\section{АННОТАЦИЯ}

Данная статья рассматривает сложившуюся ситуацию семьи в условиях трансформированного общества. С целью изучения мнения населения страны по вопросам создания семьи, принятия решений о вступлении в брак, предполагаемом количестве детей и других вопросов был проведен опрос среди представителей возрастных категорий от 16 до 60 лет.

\section{ABSTRACT}

This article examines the current situation of the family in a transformed society. In order to study the opinion of the country's population on issues of creating a family, making decisions on marriage, the estimated number of children and other issues, a survey was conducted among representatives of age categories from 16 to 60 years.

Ключевые слова: Семья, брак, родитель, дети, счастье, развод.

Keywords: family, marriage, parent, children, happiness, divorce.

Одной из характеристик демографической структуры является брак, который позволяет адекватно охарактеризовать семейные отношения, культурные нормы полового поведения и процессы воспроизводства населения. Количество заключаемых браков и разводов, темпы их роста (или снижения), оказывают сильное влияние на рождаемость в стране. Однако современное состояние семейных отношений сильно отличается от традиционных, которые были сформированы на протяжении предыдущих десятилетий советского периода.

Социально-демографическая трансформация и изменения в казахстанском обществе в постсоветский период внесли значительные изменения в традиционную модель брачно-семейного поведения. Традиционная ментальность в вопросах семейных отношений мусульман и представителей других национальностей, проживающих в Казахстане, стала меняться под влиянием западных ценностей и норм. Трансформировались и упростились многие элементы народных традиций и обычаи. Стало нормой начинать семейную жизнь не с брака, а совместного проживания, реже вступать в брак. Нормой стал и развод, в том числе и при наличии детей в семье. Также участились и случаи рождение детей вне брака и рождения в более поздние сроки, снижение общего числа детей в семьях. По данным экспертов, каждая третья семья в Казахстане распадается. При этом, чаще всего на развод подают люди в возрасте от 30 до 34 лет, которые прожили в браке пять - девять лет и разводов в два раза больше в городе, чем на селе. Надо отметить и тот факт, что у 32 тысяч человек разведенных за семь месяцев 2018 г. у 19 тысяч были дети, что естественно приводит к росту доли неполных семей.

Для изучения мнения населения страны по вопросам создания семьи, приятия решений о вступлении в брак, предполагаемом количестве детей и др. был проведен опрос среди представителей разных возрастов.

Так, для уточнения вопроса, кто же в семье (родители или их дети) принимают решение о вступлении в брак, респондентам в возрасте от 16 до 30 лет был задан: «Кто может за Вас принимать решение о создании Вами семьи? 
Таблица 1

Опрос о создании семьи

\begin{tabular}{|c|c|c|c|c|c|}
\hline & \multicolumn{3}{|c|}{ Вопрос: Кто может за Вас принимать решение о создании Вами семьи? } \\
\cline { 2 - 6 } & Варианты ответов & $16-20$ & $21-25$ & $26-30$ & $16-30$ \\
\hline 1 & родители & 5,5 & 5,5 & 9,5 & 6,4 \\
\hline 2 & я сам вместе с родителями & 44,5 & 31,4 & 44,2 & 39,8 \\
\hline 3 & $\begin{array}{c}\text { у меня есть право решать это самостоятельно, } \\
\text { потому что это моя жизнь }\end{array}$ & 50,0 & 63,1 & 46,3 & 53,8 \\
\hline
\end{tabular}

Результаты показывают, что решение о вступлении в брак в разных возрастных группах принимается по-разному. Большую самостоятельность в принятии решений демонстрируют молодые люди в возрасте от 21 до 25 лет $(63,1 \%)$ и 30-40 лет $(53,8 \%)$. При этом, у этой же возрастной группы значительные показатели и по варианту ответа «я сам вместе с родителями». По полученным данным видно, что практически по всем группам роль родителей в принятии решений значительна. Эти показатели колеблются в пределах 31,4\% до 44,5\%.

Следует отметить, что в современном обществе прослеживается не совсем здоровая тенденция отрицания потребности в принадлежности к семье, когда члены семьи пытаются строить свою жизнь самостоятельно без поддержки родственников. Об этом свидетельствуют полученные данные. Так, 53,8 \% молодых людей в возрасте от 16 до 30 лет готовы к принятию решения о вступлении в брак самостоятельно.

По полученным данным также можно сделать вывод о том, несмотря на то, что более половины участников опроса готовы к самостоятельному принятию решения, все же почти $40 \%$ участников принимают решение о создании семьи вместе с родителями и другими членами семьи. И это было вполне ожидаемо, так как благодаря функции взаимной зависимости в семье, ее члены способны выжить, так как обеспечение базовых физиологических потребностей (обеспечение пищей, жильем, материально благополучие) и психологических потребностей (потребность в любви, поддержке, заботе, самореализации) происходит в семье. Семья была и остается главной ценностью людей и тенденции к индивидуальности и автономии человека не всегда находят реализацию внутри семьи, так как семья всегда была и остается базовым составляющим человеческого бытия.

Отход от традиционной модели брачности к внебрачному сожительству, стремление вступить в официальный брак раньше оптимального возраста (до 20 лет) либо позже (после 30 лет), как было сказано выше, стали приемлемой. Также социальной нормой стала и проблема, нежелания вступать в брак. С целью выявления причин данного явления, респондентам был задан вопрос: «если не женаты/не замужем, в чем основные причины?»

Таблица 2

Опрос о причине несоздании семьи

\begin{tabular}{|c|c|c|c|c|c|c|}
\hline \multirow{2}{*}{ № } & \multicolumn{5}{|c|}{ Вопрос Если не женаты/не замужем, в чем основные причины? } \\
\cline { 2 - 7 } & Варианты ответов & $16-20$ & $21-25$ & $26-30$ & $30-40$ & $16-40$ \\
\hline 1 & Отсутствие жилья & 10,7 & 15,2 & 16,3 & 21,9 & 14,3 \\
\hline 2 & Отсутствие постоянных доходов (работы) & 13,8 & 10,5 & 9,9 & 11,4 & 11,9 \\
\hline 3 & $\begin{array}{c}\text { Высокий уровень предъявляемых требований } \\
\text { к современным девушкам, мужчинам }\end{array}$ & 8,2 & 16,2 & 14,9 & 13,3 & 12,1 \\
\hline 4 & $\begin{array}{c}\text { Низкая вероятность нахождения семейного } \\
\text { партнера по месту жительства }\end{array}$ & 6,8 & 7,1 & 12,1 & 5,7 & 7,6 \\
\hline 5 & $\begin{array}{c}\text { Необходимость улучшения материального } \\
\text { положения }\end{array}$ & 12,7 & 17,1 & 11,3 & 16,2 & 14,1 \\
\hline 6 & $\begin{array}{c}\text { Высокая сепень отвественности за создание } \\
\text { семьи, не встретил еще подходящего партнера }\end{array}$ & 13,6 & 21,4 & 25,5 & 20,0 & 18,5 \\
\hline
\end{tabular}

Согласно полученным данным, самый высокий результат по варианту ответа «Отсутствие жилья» у группы респондентов от 30 до 40 лет (22\%). Самый низкий показатель (10,7\%) в возрастной категории от 16 до 20 лет. Примерено распределились ответы $(15,2 \%$ и $16,3 \%)$ у представителей от 21 до 30 лет. В целом, по все возрастным группам, на данный вариант ответа пришлось 14,3\%. Примерно такие же показатели $(14,1 \%)$ по все возрастным группам по варианту ответа «Необходимость улучшения материального положения». А самое большое количество ответов приходится, как и по первому варианту ответов, на представителей возрастной группы от 30 до 40 лет (16,2\%). Напрашивается вывод о том, что чем старше возраст репондентов, тем большая потребность в улушении жилищных условий и приобретении жилья. Полученные данные свидетельствуют о том, что представители данной возрастной категории - это уже состоявшиеся люди, которые предпочитают не жить с родителями и не хотят скитаться по съемным квартирам. И это вполне нормальная ситуация 
Варианту ответа «Отсутствие постоянных доходов (работы)» у самой молодой части респондентов от 16 до 20 лет (14\%).

По мнению экспертов, вторая причина несчастливых браков это легкомыслие. Многие путают страсть, увлечение с взаимоотношениями. Отрадно было отметить, что согласно полученных данных, достаточно большое количество молодых людей осознают, что создание семьи это большая ответственность. И это чувство, согласно полученным данным» больше всего присуще респондентам в возрасте от 26 до 40 лет. Так, по возрастной группе от 26 до 30 лет данный показатель составил 25,3\% и от 30 до 40 лет $20 \%$. Самые низкие показатели выявлены у самых молодых. Это группа респондентов от 16 до 20 лет - 13,6\%. В целом, по данному показателю по всем возрастным группам результаты составили $18,5 \%$. И данный показатель является лидирующим, среди других вариантов ответов, не считая результатов по варианту ответа «Другое» $(21,3 \%)$. По данной позиции лидирует самые молодые респонденты в возрасте от 16 до 20 лет. Да, это и понятно, в возрасте сложно дать ответы на такие серьезные вопросы.
Ответы на вопрос «Высокий уровень предъявляемых требований к современным девушкам, мужчинам» распределились следующим образом (по степени возрастания):

$\checkmark$ от 16 до 20 лет - 8,2\%;

$\checkmark$ от 30 до 40 лет - $13,3 \%$;

$\checkmark$ от 26 до 30 лет - 14,9\%

$\checkmark$ от 30 до 40 лет - 16,19\%

Результаты позволяют предположить, что чем старше становиться человек, тем труднее создать семью, так как с возрастом накапливается определенный жизненный опыт, у большинства молодых людей уже складывается устойчивый взгляд на любовь, более трезво оценивают новые отношения и т.д.

Вступая в брак, молодые мечтают создать счастливую семью. Что в понимании молодых людей «счастливая семья»? Для получения ответа респондентам был задан вопрос: «Что для Вас понятие «Счастливая семья?» с заранее заложенными вариантами ответов. Респондентам можно было выбрать два варианта ответа. Результаты ответов представлены в таблице 3 .

Таблице 3

Опрос о понимании счастливой семьи

\begin{tabular}{|c|c|c|c|c|}
\hline \multirow{2}{*}{ № } & Вопрос : Что для Вас понятие «Счастливая семья» (можно выбрать два варианта ответа) \\
\cline { 2 - 5 } & Варианты ответов & $26-30$ & $41-50$ & $51-60$ \\
\hline 1 & Любовь, взаимопонимание, взаимоподдержка & 40,0 & 16,0 & 16,0 \\
\hline 2 & Иметь много детей & 6,0 & 15,3 & 15,3 \\
\hline 3 & Достаток, жилье & 15,9 & 33,9 & 33,9 \\
\hline 4 & Дружная семья, родители, солидарность родных & 25,3 & 4,9 & 4,9 \\
\hline 5 & Возможность достичь высокого уровня, иметь качественный \\
& уровень жизни & 9,9 & 21,9 & 21,9 \\
\hline 6 & Религиозная семья, забота о других & 2,9 & 8,0 & 8,0 \\
\hline
\end{tabular}

По полученным данным видно, взрослого поколения (от 41 до 60 лет) понятие «счастливая семья» это прежде всего, иметь «достаток, жилье», «возможность достичь высокого уровня, иметь качественный уровень жизни». Эти варианты ответа имеют наиболее высокие показатели. Надо отметить, что четка прослеживается единтичность в ответах у возрастных групп от 41 до 50 и 51 до 60 лет. Как выявлено, что ответы по всем вариантам совпадают.

Можно сделать вывод о том, что люди этого возраста смотрят на жизнь прагматично. И это закономерно. Так как ценности индивидульаной жизни и материального благополучия являются объективно необходимым условиям в условиях рыночного, социально ориентированного хозяйства.

Такие семейные ценности как любовь, взаимопонимание, взаимоподдержка наиболее важны для молодежи от 26 до 30 лет. Показатели по данному варианту ответа составили 40,0\%. Это, пожалуй, самый высокий показатель из всех предложенных вариантов ответов по всем возрастным категориям. У двух других групп этот показатель составляет лишь 16,0\%.

Настораживает тот факт, что «дружная семья, родители, солидарность родных» ассоциируется с понятием «счастливая семья», только у молодых. Его значение составляет 25,3\%, тогда как у взрослого поколения данный показатель совсем незначителен 4,96\%. Понятие «счастливая семья», у большому сожалению, практически не отождествляется с многодетной семьей. Так, у респондентов 26 до 30 лет показатели по варианту ответа «иметь много детей» составили только 5,9\%, а у старшего покаления всего $15,3 \%$. 